\title{
Whole-system thinking, development control, key barriers and promotion mechanism for $\mathrm{EV}$ development
}

\author{
Chunlin GUO (ه), Ching Chuen CHAN
}

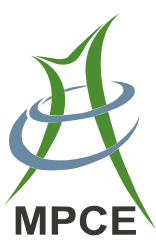

\begin{abstract}
Electric vehicles (EVs) have received significant attention because of the potential energy savings and emission reductions they enable. However, current studies and demonstrations have focused mainly on specific technologies and equipment types, which cannot in themselves solve the predicaments facing EVs. This study points out that EVs will form a large, complex system that needs to be optimized over different aspects to compete with traditional vehicles. Therefore, wholesystem thinking is needed to support the development control of EVs, with a broader scope than operational control, and the core issue is the interaction between EVs and power grid, including their coordinated development and operational management. For development control of EVs, a target system and a step-wise optimization method are presented, as well as the basic principles for designing the target system. There are two key barriers in EVs' development: the research and mass production of highperformance power batteries, and the formulation of a favorable mechanism to capture benefits and encourage development. To address the problems of EV development, a promotion method that combines franchising with moderate competition is proposed. The concepts and methods developed in this study can facilitate the research and development of EVs.
\end{abstract}

CrossCheck date: 15 January 2015

Received: 20 September 2014/ Accepted: 29 December 2014/ Published online: 8 April 2015

(C) The Author(s) 2015. This article is published with open access at Springerlink.com

C. GUO, State Key Laboratory of Alternate Electrical Power System with Renewable Energy Sources, North China Electric Power University, Beijing, China

$(\bowtie)$ e-mail: gcl@ncepu.edu.cn

C. C. CHAN, Department of EEE, University of Hong Kong,

Hong Kong, China
Keywords Electric vehicles, Charging infrastructure, Whole-system thinking, Key barrier, Development route

\section{Introduction}

The depletion of petroleum resources and worsening environmental pollution have encouraged alternatives to traditional vehicles based on combustion engines. As a consequence of technological improvements, the first mass-market electric vehicles (EVs) are now being introduced and greater market penetration can be expected. Now, EV research and policy are receiving substantial attention all over the world. Many countries have formulated their own policies and conducted different types of demonstration project to promote the development of EVs. Almost all international automotive giants such as GM, Ford, Daimler-Chrysler, and Toyota have invested huge resources in development of the next generation of EVs.

In China, a 'new energy' automotive industry focused on EVs is being fostered with government support as one of seven strategic emerging industries. The government is currently promoting a 'Ten Cities \& Thousand Vehicles program' and issued an ambitious plan which recommends that the cumulative production of EVs should reach 500000 units by 2015. The local governments in Beijing, Shenzhen and Hangzhou, as well as enterprises such as the State Grid Corporation of China, are promoting business models such as battery rental and centralized management, and have conducted many demonstration projects.

However, even though significant resources have been invested to promote EVs, the development of the Chinese EV industry remains slow. By the end of 2013, only approximately 10000 new energy vehicles were delivered in 25 demonstration cities in China. The construction of charging infrastructure has also failed to progress as rapidly as hoped. 
EV development in the US and Europe also remains unsatisfactory. The US Advanced Battery Consortium, composed by the 'Big Three' automotive manufacturers (GM, Ford, and Chrysler) and a few National Laboratories belonging to the US Department of Energy (DOE), established a set of performance targets of power batteries in the early 1990s. However, even the lowest mid-term goals are still challenging with today's technology. The DOE has reduced its research support for new energy vehicles several times.

Obviously, there are still a lot of problems that need to be dealt with before the large-scale deployment of EVs, and more research and development must be carried out to address them. Furthermore, as shown by a growing amount of research, the development of electric vehicles requires whole-system thinking to guide its top-level design. So, this paper discussed such issues of system level of EV development, including systematic thinking, development control, key barriers, etc. The concept and method gained here would be able to facilitate the research and development of EVs.

\section{Necessity of whole-system thinking}

\subsection{The large complex system that EVs will form}

\subsubsection{Basic parts of the EV operating environment}

Much literature has discussed the architecture and main issues related to EV system. The vehicle characteristics, the grid-connection or electric vehicle supply equipment, the building loads and generators, the local distribution system, and energy markets must operate well together in a complex and large EV system [1]. By virtue of being equipped with a battery, if a layer of communication exists between the system operator and the EV, the EVs are potentially capable of having their electricity requirements being served according to a pre-established schedule, and even of injecting energy back into the grid in cases where the electricity demand is high or intermittent generation output is low [2]. For example an operational framework for the implementation of a charging management model has been presented based on multi-agent system (MAS) technology [3].

All these authors point out that the relationships around EVs are very complex [4]. Figure 1 shows the overall structure of the operating environment of EV technology, which consists of three parts, including the EV, charging infrastructure and power grid.

The EV part of this system includes components such as the power battery, the converter, the driving motor, vehicle integration and compatibility. These are serially connected and form a relatively independent system. This part is

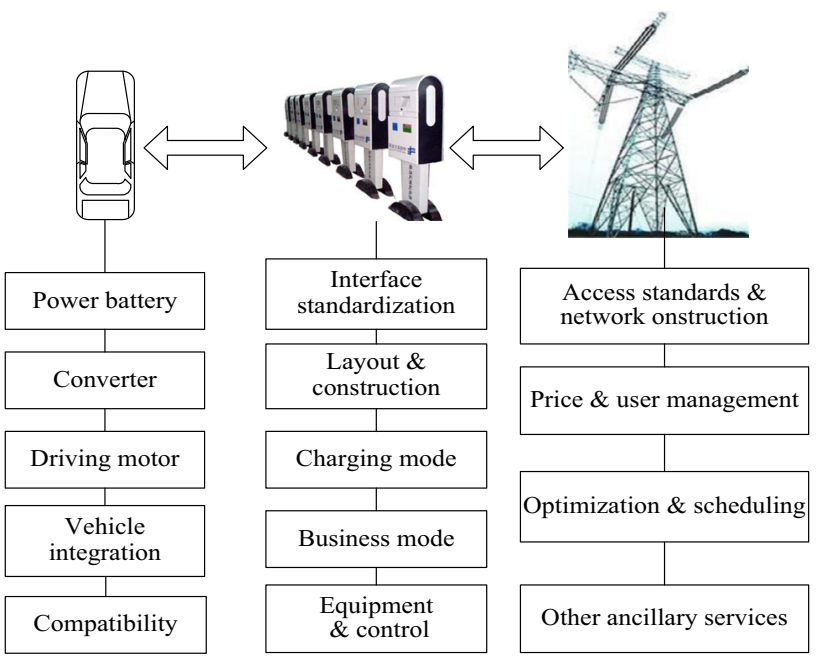

Fig. 1 Basic links in the EV operating system

primarily concerned with equipment and technology issues, where the power battery is both the weakest link and one of the bottlenecks for the entire system.

The charging infrastructure includes links components as interface standardization, layout and construction, charging model, business model, equipment types and the control system. This part is primarily related to business and operation.

There are two key issues.

1) The charging model, operating model and business model have not been clearly identified; thus, it is difficult to make decisions.

2) The infrastructure requires a high investment over a long period and is intertwined with many complex external factors, such as land utilization, resulting in complex relationships of benefits and restrictions.

A vertically integrated power grid includes components such as access standards and network construction, electricity pricing and user management, optimization and scheduling, and other ancillary services. Disaggregated power grids separate some of these responsibilities, such as pricing, but the essential functions are the same. This part is concerned with many complex problems of technology, control and operation. The core issue for EVs is to improve their convenience and maximize their system benefits, by coordinating EVs with the power grid.

\subsubsection{Main couplings and performance requirements in the EV operating environment}

As Fig. 2 shows, besides different physical devices, there are many entities in the EV system such as the generation companies (GENCOs), transmission system operators (TSO), 


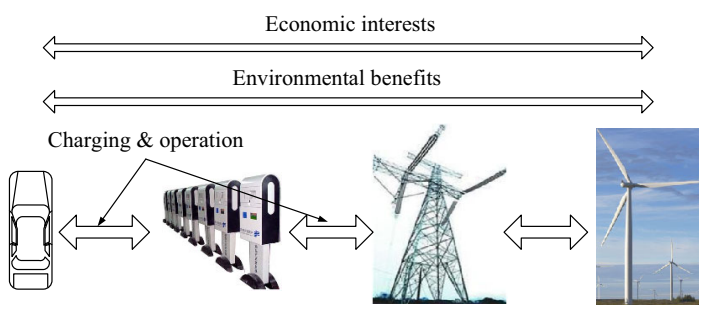

Fig. 2 Major coupling chains in EV system

distribution system operators (DSO), charging point managers (CPM), and EV users. And there are multiple relationships among different components and entities in the EV system, which are dominated by three coupling chains: charging and operating, environmental benefits and economic interests.

The charging and operating chain is composed of the hardware connections and operating interactions during the process of charging and power supply. This chain requires convenient charging and simple operations, so as to reduce the costs and time expended. The environmental benefits chain is based on energy conservation and emission reduction, which are both major driving forces for EV development. This chain requires the scheduling of new energy for global optimization. The economic interest chain connects the economic performance of the different sections. This chain must facilitate the formation of a sustainable business model for EVs and is the key issue that determines the viability of EV development.

The outcomes of these three coupling chains are convenience, environmental conservation and economy, which are the performance requirements of EV system. These couplings and performance requirements connect all parts of EV operation abovementioned to form a large, complex and interactive system.

\subsection{Whole-system thinking for EV development} and the challenges it brings

Because of the complicated structure and coupling relationships mentioned above, rather than an issue of technologies and devices, EV development is a problem of the construction and overall optimization of a large complex system, which needs whole-system thinking that will bring huge challenges to research and development of electric vehicles.

In earlier studies, EV and grid are often regarded independently, where EV simply consumes electricity from the power grid and pays as an ordinary consumer. For example, in comparisons of energy consumption, cost and environmental benefits of EVs and internal combustion engine vehicles (ICEVs), some articles conclude that pure electric cars and hybrid vehicles are suitable for short-term and medium-term development, and fuel cell vehicle are suitable for long-term development, while the driven distance greatly affects total $\mathrm{CO}_{2}$ emissions and user cost [5-7].

However, as research deepens, people gradually realize that EV development involves optimization of the power grid and new energy, where EVs, charging infrastructure, the power grid and renewable power generation must be considered as a whole to achieve global optimization. First of all, in technical and operational aspects, smart charging, vehicle-to-grid (V2G), vehicle-to-home (V2H), battery replacement and many other technologies and operation schemes are proposed. For example, Ref. [4] puts forward an integrated method to study EV business models, and provides three morphological boxes of vehicle and battery, charging infrastructure, and system services, which have different characteristics and possible options and are helpful for the formulation and analysis of alternative applications and business models. Ref. [8] proposes a conceptual regulatory framework for EV charging, introduces EV charging managers and EV integrators, and analyzes the market functions and business relationships to support charging at home, at public charging on the street, and at specific charging station.

With respect to economics, power grid impacts, environmental benefits and other aspects, research more often takes a holistic viewpoint. Ref. [5] uses data from Western Australia to calculate the benefits of V2G in short-term market arbitrage, provision of spinning reserve, load following, and participating in demand-side management, and points out that currently EVs can be used for demand-side management but are not suitable for other services. Ref. [9] proposes a comprehensive method for assessing the impact of EV penetration on investment and network losses of two actual distribution networks, and pointed out that smart charging can reduce new investment by $60 \%-70 \%$ and decrease network losses by $40 \%$. Based on a stochastic model of Western European travel, Ref. [10] studied the influence of plug-in hybrid EVs (PHEVs) on Belgian electricity demand and showed that, although it is necessary to manage the influence through smart charging, timeof-use electricity price would lead to negative peak load. Other literature analyzed the costs and benefits of various methods of EV charging. A case study of fast charging in Germany shows that, a market-driven roll-out of fast charging infrastructure is unlikely to be profitable in Germany, and the EV adoption rate is the main risk factor to determine [11]. A stochastic optimization algorithm is presented in [12] with the aim of maximizing the use of renewable energy, using a Monte Carlo simulation of transportation patterns.

However, although the scientific community has begun to study EVs as a system, there are still many problems with these studies that need to be addressed. For example, a 
lot of literature takes either predetermined prices or an electricity market as the premise to analyze and optimize the user and grid benefits of EVs. However, what can finally be obtained this way are local economic and environmental benefits, which are different from global benefits and optimization from the point of view of the whole system described above. Studies focused on aspects of charging can also only reflect limited economic and environmental benefits.

In general, being a new form of large complex system, electric vehicle development is facing new historical conditions and challenges. First of all, electric vehicles are not simply a refit and transformation of fuel vehicles, but require revolutionary changes in the life-cycle of vehicles in our society, including production and operation. At the same time, sustainable development has become the theme of present times and requires a unified understanding of economic, environmental and social benefits of electric vehicles. Moreover, the EV production and operating environment involves many participants, with complex relations between their interests, and requires therefore a high level of judgment to be applied to achieve optimization of multiple values.

Therefore, not only in technology, but also in economic and environmental aspects, EV development requires whole-system thinking to guide its analysis and top-level design, so as to formulate a reasonable development route, business model, and policy system. This presents a huge challenge for the development and study of EVs.

\subsection{Relationships between the EV system and the power grid}

Among all the aspects of EV development, a harmonious relationship with the power grid is of key importance. Wide area controllers are necessary to manage grid-to-vehicle $(\mathrm{G} 2 \mathrm{~V})$ or vehicle-to-grid (V2G) power transactions, that is, charging and discharging cycles of the plug-in EVs respectively [13]. In electricity markets, it is economically feasible to use electric vehicles to provide frequency modulation and spinning reserve service most likely through an aggregator to achieve sufficient scale for market participation. Frequency modulation services provide better financial returns than spinning reserve services [14]. Integration of EV charging and discharging facilities with RES gives a helpful synergy in micro grid systems [15].

To facilitate the relationship between EVs and the power grid, we should adhere to the following three principles.

1) The power grid should become a friendly access platform. This is one of the basic aims of power system development, and is accentuated by the current smart grid. The power grid should become a more open, safer and highly efficient energy exchange platform, making use of its huge terminal network and operating system to support EV development.

2) EVs should satisfy the norms and requirements of the power system, and become well-behaved loads. Compared to other loads, EVs have no special requirements for power quality. On the rare occasions when an EV is not available because of a power outage, the user can often choose alternate travel modes or can cancel his or her trip plans; generally, there would be no unavoidable great losses. In contrast, the enormous scale of the power system makes it difficult to estimate and manage the losses caused by breakdowns. Obviously, the safety and reliability of the power system should not be affected by EVs. Additionally, from the perspective of technical considerations, EVs can deal with harmonics and fluctuations that they cause by advanced converters and control technology.

3) Scheduling should be employed to ensure mutual benefit and sustainable development. EVs have excellent flexibility in their charging times; thus, EVs could be included in power system scheduling, lower the peak-valley difference and increase the consumption of new energy to provide additional benefits. As such, they would be useful resources under a competitive business model.

In short, the power system would provide the most essential support for EVs. A harmonious relationship with the power system has the potential to effectively accelerate EV development; otherwise, EV development will be impeded.

However, as some literature has pointed out, there are many preconceptions and barriers that inhibit a larger market penetration of EVs. The establishment of this mutually beneficial relationship is an arduous whole-system project, which involves multiple participants, in addition to complex technical and economic problems. Tremendous effort is required to reach consensus on the way forward, to form corresponding policies and regulations, and to put those policies and regulations into practical operation.

\section{Realization of whole-system thinking by development control and the key barriers}

\subsection{Development control and the realization of whole-} system thinking

In 1948, Wiener published Cybernetics: Or the Control and Communication in the Animal and the Machine and established control theory. This theory and the related methods have been widely used in almost all of the natural 
sciences and social sciences. From a control perspective, the realization of whole-system thinking requires the components, relationships between them and the overall performance of the EV system to achieve some goals, processes or trends, and is, in essence, a kind of development control. While, the formulation and implementation of a development path, business model and policy are essentially some important links and specifically realized means of development control. Therefore, we should take full advantage of system theory, cybernetics and their methods to study development control with whole-system thinking, and propose the basic ideas, implementation methods and key links of it. Then, the rules and methods obtained here will be instructive to the study of development path, business model, incentive policy for EVs.

Figure 3 shows the overall architecture of EV control. Two types of control are involved: the operational control of the physical system and the development control of the EV industry. The operational control (which lies within the dotted rectangle in the figure) comprises many controls of different layers and types, ranging from system to devices. Because numerous studies have explored this type of control, we will not provide further details here. The other type is the development control, and both types are supplementary to each other, constituting the complete control system for EVs.

Figure 3 shows an open loop/closed loop combined development control method using the target system as the core. First, the target system is established according to system requirements. Simultaneously, the system of basic principles, methods and standards is developed according to the technical and economic conditions, so that all of the scientific methods required are integrated and optimized. They are then used to formulate development planning and detailed implementation schemes, which achieve the control of the development process. Meanwhile, the closed

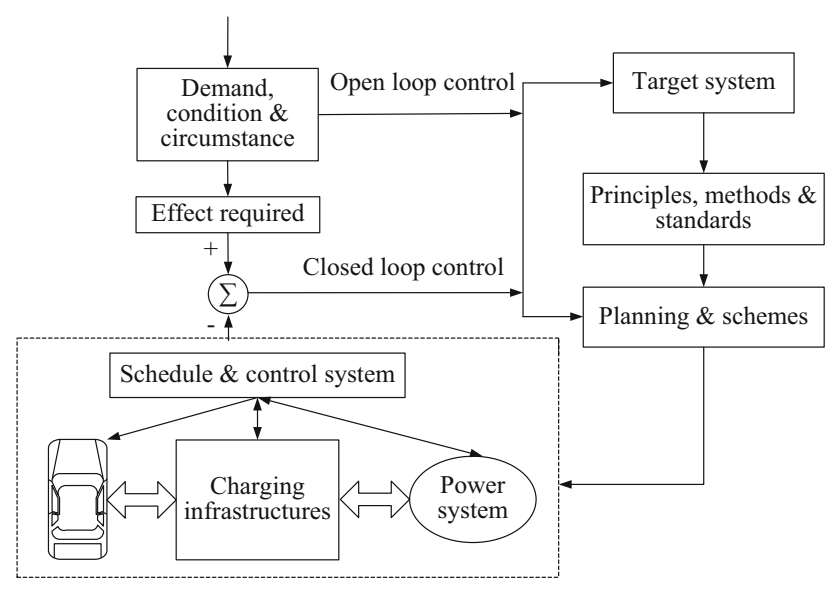

Fig. 3 Overall control architecture of EV development loop control can adjust and refine the target system, according to the difference between the actual operational effect and the required effect.

It is viable to carry out the development control of EVs based on a target system. This control method is generally used in the development of large systems and in controlled economies it has been widely used in areas such as the national economy, industry construction and infrastructure construction. For example, this method is used by the power system to develop a mature control system. In China, there are more than 3000 regulations and standards for the electricity power industry, regulating all types of plans and schemes to realize the development objectives, including safety, stability and economics.

EV development is centered on industry construction and infrastructure construction; therefore, this control method can also be used in EV development. Further, the control method not only can draw on expertise from the aforementioned fields but also can assimilate EVs into the power system, while sharing mutual benefits from the start by integrating the objectives and principles of construction, so as to better use the power system to support and promote EV development.

It is also necessary to achieve effective development control of EVs by target system. First, this is determined by the complexity, uncertainty and partial uncontrollability of the large system. For small systems, it is usually very easy to define the control targets and they tend to be simple and clear; hence, the key challenge in control is the analysis of system characteristics. However, for complex, large systems, global control and optimization are difficult to realize using a limited number of targets and control variables; a target system that is more comprehensive and can efficiently control the key processes and characteristics becomes indispensable. Second, this is also needed for EVs to compete with fuel vehicles. Only if clear and superior targets of each part of the system are proposed and reached can EVs surpass fuel vehicles.

\subsection{Requirements for the development control of EVs in competition with fuel vehicles}

Generally, it must take a long time for a large, complex system to develop to maturity, and this process is often gradual, with development being a quasi-stable process and having the following characteristics.

1) The development is relatively slow; additionally, change is scarce, and the extent of change is limited during each stage.

2) The process can provide sufficient data and experience, which may facilitate the formulation of the basic models and methods for development analysis. 
3) Because the investment is so massive, the construction period is long, and the losses engendered by adjustments for errors are significant and unacceptable. Its development control is primarily an open loop process, together with the closed loop process occasionally operating as a complement; significant alterations need to be avoided during the construction.

However, because of competition with traditional fuel vehicles, the external environment cannot allow EVs to develop in such a slow and gradual manner. Fuel vehicles have already reached maturity as a system, so EVs cannot develop widely without exceeding fuel vehicles in terms of convenience, economy and comprehensive benefits. Therefore, some special requirements are imposed on EV development.

1) EV technology must in a step-wise manner. Some sufficiently high objectives should be set at the beginning, so as to reach to economies of scale in construction as quickly as possible.

2) There are too many feasible development directions: thus, in the initial stage, the exploration and validation of the best direction and mode are more important strategic objectives than actual construction.

3) The development should enhance the usage of closed loop control: because of the absence of data and expertise, the analysis should be combined with closed loop verification to develop and refine various types of models, principles, methods and standards.

The analysis above leads to some basic principles for designing the target system for EV development.

1) The design must follow demand, and take the surmounting of fuel vehicles as the basic standard.

2) The development should be divided into different stages and be carried out step-by-step according to the goals.

3) The target system should cover all components and links shown in Fig. 1.

4) The targets relating to each link should be harmonized for coordinated development.

5) The charging infrastructure should be advanced suitably and should match with the environmental conditions.

6) The target system should be adjusted and refined according to observed changes during EV development.

\subsection{Key barriers for EV development}

There are more difficulties than envisaged need to be resolved to realize vigorous EV development and replace a notable segment of fuel vehicles. Many barriers to such an epochal transition into EVs are elucidated in recent literature, including the reluctance of existing petroleum firms and uncertain consumer attitudes. The introduction and penetration of EVs is confronted by several barriers such as immaturity of technology, fragmented infrastructure, incomplete standards and regulations, and skepticism of consumers towards an emerging technology [16]. If the subsidies provided by the government do not compensate the negative aspects of EVs' performance, they cannot be attractive and engender adequate incentive [17]. Lack of charging infrastructure and relatively high vehicle prices create challenges to EVs and affect government support policies [18].

To sum up, these difficulties are mainly covered by four aspects:

1) It is difficult to reduce the cost of EVs, because the environmental benefits are not urgent, direct, or easy to be quantified. Consequently, EVs cannot show obvious advantages; their development lacks sufficient impetus; and it is difficult to make decisions regarding EV development.

2) There are numerous viable charging models, operating models and business models, which cause difficulty in selecting a development path.

3) A sizeable and systematic demonstration project does not exist yet. Therefore, there are no fundamental data to sufficiently describe actual situations, so that it is not yet possible to verify EV studies and analyses.

4) The operating and industry chain is very long. There are many participants with complicated relationships, and the coordination among them is very difficult.

In general, there are two key barriers that are critical for the promotion of $\mathrm{EV}$ development. In terms of productivity or technology, the key barrier is the research and mass production of power batteries that can offer high energy density, power density and safety. Numerous researchers have conducted extensive studies on this topic.

In terms of production relationships and system construction, the key barrier is top-level design of development and benefit mechanisms, namely the formulation of a reasonable development path, benefit mechanisms, and regulating policies. Positive interactions must be promoted among the government, enterprises and the market. Appropriate coordination is also required among EVs, the charging infrastructure and the power grids, so as to form balanced economic interest chains, with reference to Fig. 2. The basic requirement is to reduce the uncertainty of the participants' profit and ensure a return on investment. Then, the following measures should be taken to promote the rational top-level design of the development and benefit mechanisms.

1) Conduct a thorough, comprehensive and realistic study of the development path for the entire, large EV system. 
2) Carry out a global benefit analysis and top-level design to develop suitable mechanisms, improve economic impetus for development, coordinate economic relationships, and promote the formation of viable business models.

3) Carry out comprehensive demonstrations of a variety of models with explicit objectives, plans and sufficient scales, to verify the development direction, and refine the analysis models and methods.

4) Understand the methods and expertise of fuel vehicles and the power system to assist the development of EVs.

5) Enhance the discussion among different sectors to form the consensus for reciprocity, and then turn that consensus into basic regulations, standards and concrete actions.

\section{Promoting EVs by macro motivation versus by micro intervention}

4.1 Is macro motivation or micro intervention more suitable for current demands of EV?

As many papers discuss, both EV technology and charging infrastructure require huge investments and long periods of construction; while the return is inherently slow, the risk is very high, and substantial innovation is needed in technologies and business models. In the initial stage, the insufficiency of overall profit and the risk of investment will be most severe, so that they will be too difficult for individual participants to undertake. Therefore, it is clear that strong measures implemented using a reasonable promotion mechanism are for the development of EVs.

However, selecting the best promotion mechanism for $\mathrm{EV}$ development is a difficult problem for governments, although much literature has been written about it. The morphological method aims to support companies on a strategic level with a sound concept when developing a business model, to refine first ideas and approaches and list alternatives [4]. Two new electricity market agents, the EV charging manager and the EV aggregator, in charge of developing charging infrastructure and providing charging services are introduced [8]. Interaction between government policies and performance attributes of EVs also has a significant effect on the development of the EV market [17]. EV policies focused on early adopters and niche markets would create complementary system effects that will lead to increased EV market penetration and realization of intended societal benefits [18]. An aggregator participating in the reserve market could achieve a substantial reduction of its wholesale costs, even when a capacity price for available reserve is not considered [19].
To establish an effective support policy and promotion mechanism, the most first problem that should be solved is whether macro motivation or micro intervention should be taken. According to the analysis above, in EV development control, it is necessary to explore and verify a variety of directions and modes of development, realize balance of many different links, and make timely adjustment according to real-time changes. For these issues, because developing and changing policies is a long and difficult process, it is difficult to achieve good results using incentive methods based on micro intervention, while using macro regulations to motivate and guide enterprises as they develop liberally can help to reach reasonable benefit mechanisms.

However, in current circumstances, the power industry in many countries has completely or partially regulated utilities, and faces strong technical challenges. In order to realize the liberal development of EV enterprises in coordination with utilities, major changes in policy environment are needed. Moreover, due to the large investment and long cycle of returns in developing electric vehicles and charging infrastructure, promising methods to encourage enterprises to participate in the development of electric vehicles are franchising, build-operate-transfer (BOT) and related policy tools. A scheme is suggested below which combines franchising with moderate competition.

\subsection{Promotion mechanism based on franchising}

Franchising is a well-known commercial and policy tool. It can lower the uncertainty, ensure the interest of investors by a long-term mechanism, and provide sufficient impetus, so that it can strongly promote major construction projects and scientific and technological innovation. Therefore, franchising is widely practiced in fields such as telecommunications, energy and transportation. Meanwhile, patent rights also serve as a special franchise right in related to underlying technologies.

So, in the initial stage, franchise rights could be used to promote EV development, which would achieve the vigorous development of EVs. Then, in the mature stages, when the operating models and business models have been verified, more competition can be introduced to improve efficiency.

For example, in China, it might be declared that the initial stage of EV development will take 20 years. During this period, at most $6 \mathrm{EV}$ manufacturers and 4 charging infrastructure operators will be able to obtain nationwide business licenses; further, all of these licenses will specify technologies developed in the demonstration projects. As a result, the enterprises that succeed in obtaining licences will be highly motivated, so as to powerfully promote EV development. 
In the initial stage of EV development, franchising and demonstration should be combined together to carry out comprehensive demonstrations at scale, so as to overcome the problems of existing demonstration projects that are not comprehensive due to their limited scale. The following is the specific implementation mechanism proposed.

1) Choose several demonstration cities with populations of approximately 200000; at least 20000 EVs should be introduced to the populations in each city in the project period, which should be approximately 4 years.

2) Further, determine the charging model and operating model for each project before its commencement. Then, the charging infrastructure and the smart scheduling system should be constructed thoroughly, and the corresponding pricing policy must be established, to explore and form stable business models.

3) Take the first round of public bidding to determine the EV manufacturer, the charging infrastructure operator, as well as the technical and economic requirements. The manufacturer and operator must form a partnership for bidding, and they must jointly detail the operating methods, electricity pricing and other policies that they will implement. The bidding manufacturer must promise some basic items, such as the vehicle characteristics and the maximum price, the investment that will be made, in addition to appointing the minimal development team and investment, and providing security deposits for realization of these. In return, the government should guarantee the minimum sales of manufactured EVs that meet the quality requirements, and is responsible for policy making, supervision and assessment.

4) For the initial stage, it should be defined that the franchised operation will be the only producer of EVs and charging infrastructure, and all of the manufacturers and operators with successful demonstration projects and sufficient investments are eligible to bid for franchise rights.

5) In the first bidding above, the government obtains the right to permit several enterprises to use the technologies developed in the demonstration projects. Then, the use rights of these technologies can be sold to other proper enterprises via the second round of public bidding, and the income will be used for project construction. Finally, the government and investors may form an investment committee to supervise the project and provide the franchised enterprises with qualified personnel, technologies and other support.

The above mechanism has several advantages. 1) Franchising and guaranteed sales can lower risk and ensure the interests of the manufacturers and operators. 2) By taking full advantage of public bidding, the enterprises will be driven to improve technology and reduce costs, and the best balance can be found. 3) An interest community can be formed through the transfer of the technology use rights, which may solve numerous problems, including funding, supervision, evaluation, and technology sharing. Thus, a large-scale, systematic and comprehensive demonstration can be conducted and refined as shown as in Fig. 3, and EV development can be significantly promoted.

\section{Conclusions and research suggestions}

This paper investigated some important problems of EV development such as system architecture, whole-system thinking, development control, and promotion mechanism. The major conclusions are listed below.

1) EVs will lead to a complex system with multiple links and multiple coupling chains, which needs optimization in all aspects so as to realize the objective to surpass traditional vehicles. Therefore, whole-system thinking should be enforced in the development and control of EVs.

2) Among all the aspects of EV development, the core issue is the interaction between EVs and the power grid. The power grid should become a friendly access platform; EVs should become well-behaved loads; while coordination should be adopted to realize mutual benefit, so as to take full advantage of power grid to support and promote the development of EVs. However, the realization of these is an arduous system project that needs tremendous effort from each participant.

3) Development path, business model and policy all are important links and specific means of realizing development control. Therefore, we should take full advantage of system theory, cybernetics and their methods to guide study of development control with whole-systematic thinking.

4) A development control method with a target system as the core is presented. Because of the special requirement to compete with traditional vehicles, EVs must develop in a step-wise manner with strong closed-loop control. Moreover, the basic principles for designing the target system are given too.

5) There are two key barriers to the development of EVs. In terms of productivity and technology, it is the research and mass production of high-performance power batteries. In terms of production relationships and system construction, it is the top-level design of development and benefit mechanisms, namely the formulation of a reasonable development path, benefit mechanisms, and policies, where the basic requirement is to reduce the uncertainty and ensure a return on investment.

6) EV support policies and promotion mechanisms should be based on macroscopic incentives to guide 
enterprises to develop liberally. Because of the regulation on power industry, appropriate changes in policy environment should been taken, so as to provide a suitable environment for the development of EVs.

7) Franchising was presented as the promotion mechanism most likely to achieve the vigorous development of EVs. Additionally, for the initial stage of development, a comprehensive demonstration mechanism was given that combines franchising with moderate competition.

Regarding the two key barriers above, there are two corresponding important research problems that need to be solved. The first one is battery technology and industry construction, where it is necessary to reduce the cost and enhance the performance of power batteries. New materials and structures are among the most important study directions. Only after the major breakthrough in these aspects, can the vigorous development of EV come, and can the issues of its application be solved finally. The manufacturing methods, energy management system, package technology and re-use or re-purposing of power batteries have important significance, too. Standardization system is also urgently required, so that disorderly development of incompatible products can be avoided.

The other one is the method to carry out reasonable system analysis and top-level design for EV development, so as to establish an excellent development and benefit mechanism. Although we have carried out a large number of studies and demonstrations on best development path and policy for EVs, the pace of industry development is not sufficient yet. This shows that there are still some blind areas in existing system analysis and top-level design of EVs, so more effective theories and methods are needed, and this is also a key research problem. Meanwhile, the combination of whole-system thinking and development control may have the potential to provide new ideas and tools for research in this area, and so is worthy of high attention.

Acknowledgments This work was partially supported National High Technology R\&D Program of China (863 Program) (No. 2012AA050804).

Open Access This article is distributed under the terms of the Creative Commons Attribution License which permits any use, distribution, and reproduction in any medium, provided the original author(s) and the source are credited.

\section{References}

[1] Garcia-Valle R, Peças Lopes JA (2013) Electric vehicle integration into modern power networks. Springer, New York, NY

[2] Ortega-Vazquez MA, Bouffard F, Silva V (2013) Electric vehicle aggregator/system operator coordination for charging scheduling and services procurement. IEEE Trans Power Syst 28(2):1806-1815

[3] McArthur SDJ, Davidson EM, Catterson VM et al (2007) Multiagent systems for power engineering applications-Part I: concepts, approaches, and technical challenges. IEEE Trans Power Syst 22(4):1743-1752

[4] Kley F, Lerch C, Dallinger D (2011) New business models for electric cars-a holistic approach. Energ Policy 39(6):3392-3403

[5] Mullan J, Harries D, Bräunl T et al (2012) The technical, economic and commercial viability of the vehicle-to-grid concept. Energ Policy 48:394-406

[6] Faria R, Moura P, Delgado J et al (2012) A sustainability assessment of electric vehicles as a personal mobility system. Energ Conver Manag 61:19-30

[7] Silva C, Ross M, Farias T (2009) Evaluation of energy consumption, emissions and cost of plug-in hybrid vehicles. Energ Conver Manag 50(7):1635-1643

[8] San Román TG, Momber I, Rivier M et al (2011) Regulatory framework and business models for charging plug-in electric vehicles: infrastructure, agents, and commercial relationships. Energ Policy 39(10):6360-6375

[9] Pieltain Fernández L, San Román TG, Cossent R et al (2011) Assessment of the impact of plug-in electric vehicles on distribution networks. IEEE Trans Power Syst 26(1):206-213

[10] Geth F, Willekens K, Clement K, et al. (2010) Impact-analysis of the charging of plug-in hybrid vehicles on the production park in Belgium. In: Proceedings of the 15th IEEE mediterranean electrotechnical conference (MELECON'10), Valletta, Malta, 25-28 Apr 2010, pp 425-430

[11] Schroeder A, Traber T (2012) The economics of fast charging infrastructure for electric vehicles. Energ Policy 43:136-144

[12] Pantoš M (2011) Stochastic optimal charging of electric-drive vehicles with renewable energy. Energy 36(11):6567-6576

[13] Mitra P, Venayagamoorthy GK (2010) Wide area control for improving stability of a power system with plug-in electric vehicles. IET Gener Transm Distrib 4(10):1151-1163

[14] Rong LL, Wen FS, Xue YS (2013) Economic analysis of ancillary service provision by plug-in electric vehicles. Autom Electr Power Syst 37(14):43-49 (in Chinese)

[15] Xiao XN, Chen Z, Liu N (2013) Integrated mode and key issues of renewable energy sources and electric vehicles' charging and discharging facilities in microgrid. Trans China Electrotech Soc 28(2): $1-14$

[16] Steinhilber S, Wells P, Thankappan S (2012) Socio-technical inertia: understanding the barriers to electric vehicles. Energ Policy 60:531-539

[17] Zhang X, Wang K, Hao Y et al (2013) The impact of government policy on preference for NEVs: the evidence from China. Energ Policy 61:382-393

[18] Green EH, Skerlos SJ, Winebrake JJ (2014) Increasing electric vehicle policy efficiency and effectiveness by reducing mainstream market bias. Energ Policy 65:562-566

[19] Bessa RJ, Matos MA (2013) Optimization models for EV aggregator participation in a manual reserve market. IEEE Trans Power Syst 28(3):3085-3095

Chunlin GUO was born in Hunan Province in China, on February 4, 1975. He received the B.Sc. degree and Ph.D. degree in electrical engineering from Tsinghua University, Beijing, China, in 1998 and 2003, respectively. Now, he is an associate professor of the School of Electrical and Electronic Engineering, North China Electric Power University, Beijing, China. His research interests include electric vehicle charging and its interaction with grid, analysis and control of FACTS and power quality control. 
Ching Chuen CHAN has over 10 years of industrial experience and over 35 years of academic experience. He is currently the honorary professor and the former head of department of Electrical and Electronic Engineering, the University of Hong Kong, Hong Kong, China. He is the founding president of the International Academy for Advanced Study, China, the cofounder and the rotating president of the World Electric Vehicle Association, and the president of the Electric Vehicles Association of the Asia Pacific. Dr. Chan is a fellow of IEEE/IEE, and an academician of the Royal Academy of
Engineering, U.K., the Chinese Academy of Engineering, the Ukraine Academy of Engineering Sciences, the Institution of Electrical Engineers (IEE), and the Hong Kong Institution of Engineers. He has delivered lectures on electric vehicles worldwide. He was named Father of Asian Electric Vehicles by the magazine Global View in 2002. He was also named BPitamaha (Grandfather) of Electric Vehicle Technology in India at the IEEE Conference on Electric and Hybrid Vehicles in 2006. He received the IEE International Lecture Medal in 2000. 